\title{
Relação de longo prazo entre os preços da carne bovina: evidências empíricas
}

\author{
Heberth Duarte dos Santos \\ Sociólogo e Economista. Mestre em Estudos Populacionais e Pesquisas Sociais pela Escola \\ Nacional de Ciências Estatísticas/IBGE \\ E-mail:hbtsantos@msn.com
}

\author{
Waldemiro Alcântara da Silva Neto \\ Doutor em Economia Aplicada. Programa de Pós-Graduação em Economia - \\ PPE/FACE/UFG \\ E-mail: netoalcan@gmail.com
}

Resumo: Tendo como pano de fundo a importância da pecuária de corte bovina na formação do Produto Interno Bruto do Estado de Goiás, este estudo tem como objetivos: analisar a existência de relação de longo prazo entre os diferentes níveis de preço da carne bovina em Goiás e demonstrar e analisar o sentido da causalidade entre os preços, seu processo de transmissão e medir as elasticidades-preço da carne. Para tanto foram usadas as séries mensais de preços do bezerro, do boi gordo e do varejo, de 2001 a 2011 para o estado de Goiás. O método usado foi baseado na análise de séries temporais: teste de raiz unitária, cointegração, causalidade de Granger, decomposição histórica da variância e função de resposta ao impulso. Os resultados revelaram que não há, neste período, relação de longo prazo entre os preços analisados e que o varejista pode estar se apropriando das altas nos preços da demanda. Ainda, há um indicativo de que esteja ocorrendo na cadeia de carne bovina de Goiás o que já tem sido apontado como recorrente na cadeia em nível nacional: baixa coordenação, assimetria e apropriação dos ganhos por parte do agente da cadeia mais bem estruturado: o varejista.

Palavras chaves: Carne Bovina; Preço; Cointegração; Goiás

\begin{abstract}
Against the backdrop of the importance of livestock for slaughter cattle in the formation of the Gross Domestic Product of the State of Goiás, this study aims to: analyze the existence of long-term relationship between the different levels of beef prices in Goiás and demonstrate and analyze the direction of causality between prices, the process of transmitting and measuring price elasticities of meat. Therefore, we used the monthly series of calf prices, live cattle and retail, from 2001 to 2011 for the state of Goiás. The method used was based on the analysis of time series: unit root test, cointegration, Granger causality, historical decomposition of variance and impulse response function. The results revealed that there is, at this time, long-term relationship between prices analyzed and that the retailer may be appropriating the price spikes in demand. Still, there is an indication that is occurring in the chain of beef Goiás what has already been touted as a recurring chain nationwide: low coordination, asymmetry and appropriation of earnings by the actor in more structured: the retailer.
\end{abstract}

Key words: Beef; Price; Cointegration; Goias

JEL Classification: Q13; Q18 
p. 3 - Relação de longo prazo entre os preços da carne bovina: evidências empíricas.

\section{INTRODUÇÃO}

A economia brasileira no último biênio tem desacelerado como mostram os dados do Instituto Brasileiro de Geografia e Estatística - IBGE (2013). O crescimento do Produto Interno Bruto (PIB) foi de apenas 2,7\% em 2011 e em 2012 estima-se um crescimento próximo a 1\%. O agronegócio, em contrapartida, apresentou crescimento significativo, alcançando, em 2011, 4,38\%, segundo o Centro de Estudos Avançados em Economia Aplicada - CEPEA (2012). Em Goiás, esse segmento é muito importante para a economia e tem apresentado resultados expressivos e em ranking realizado com informações do PIB de 2009 Goiás é o nono estado da federação que mais contribuiu para a formação do PIB nacional. À época, isso equivalia a 2,64\% do PIB brasileiro e somava $\mathrm{R} \$ 85,62$ bilhões, contudo, quando observado apenas o PIB da agropecuária, o estado passa a contribuir com $6,74 \%$ e a figurar como o 6 o estado a mais contribuir com o PIB deste setor (Secretaria de Planejamento do Estado de Goiás- SEPLAN-GO, 2011).

No que diz respeito à pecuária de corte bovina, objeto de estudo deste artigo, dados do IBGE (2013) informam que foram abatidos no Brasil, em 2010, um total de 29,2 milhões de cabeças de gado. Destes, cerca de 9\% (2,6 milhões) em Goiás, o que dá uma boa dimensão da importância econômica desta atividade.

Segundo o Ministério da Agricultura, Pecuária e Abastecimento - MAPA (2011), a projeção de crescimento na produção de carne bovina para o período de 2010/2011 a 2020/2021 é de 2,2\% ao ano. O que significa dizer que a produção de carne bovina, em toneladas, deverá passar das atuais 9 mil para 11,3 mil, em 2021. Ainda em dados desse estudo, estima-se que haverá um aumento de 2,3\% no consumo interno da carne bovina, que passaria das atuais 7,3 mil toneladas, para 9,4 mil em 2021, tendo as exportações um aumento anual estimado em 2,6\%, passando, das atuais 1,8 mil toneladas, para 2,3 mil em 2021.

Diante da importância da pecuária na geração de superávits comerciais, na geração de emprego e na dinâmica econômica do país e de Goiás, estudos que busquem compreender esse setor do agronegócio são de grande importância para a academia e para o próprio setor de carne bovina. Assim, o objetivo geral deste artigo é analisar a relação de longo prazo dos preços da carne bovina para o produtor e para o varejo no estado de Goiás entre os anos de 2001 e 2011. Especificamente, pretende-se: através da análise de cointegração, verificar se há relação de longo prazo entre os diferentes níveis de preços e analisar o processo de transmissão e o comportamento do preço da carne bovina na última década em Goiás.

Além dessa introdução, esse artigo contém uma breve revisão de literatura sobre estudos que tratam da relação de longo prazo entre preços de produtos agropecuários, na seção dois. A terceira trata do material e métodos e na quarta seção, têm-se os resultados e discussões. Por fim, as considerações finais na última.

\section{REVISÃO DE LITERATURA}

Utilizando-se de metodologia semelhante a proposta neste artigo, Silva et al. (2003) avaliaram a existência de relações de cointegração ou de equilíbrio de longo prazo 
entre os preços nominais da soja praticados nos mercados brasileiro e norte americano durante o período compreendido entre janeiro de 1995 e agosto de 2002. Segundo os autores, a avaliação da existência de relações de cointegração ou de equilíbrio de longo prazo possibilita ao investidor conhecer antecipadamente o comportamento dos preços das commodities (no caso, a soja) e a relação que se estabelece entre os preços praticados nos mercados emergentes e norte-americano, tornando assim possível a construção de estratégias para se proteger de possíveis oscilações que possam comprometer os fluxos futuros de seus rendimentos. Os resultados obtidos evidenciam a existência de relações de equilíbrio de longo prazo (cointegração) entre os preços da soja negociados na economia brasileira e os preços cotados na economia americana. 0 coeficiente de ajustamento encontrado foi de 0,8483 , o que significa dizer que, no longo prazo, variações de preços desse produto nos Estados Unidos são transferidas, em média, $84,83 \%$ para os preços domésticos no Brasil.

Margarido e Fernandes (2001) analisaram a elasticidade da transmissão de preços no mercado de grão de soja entre o porto de Rotterdam, na Holanda, e o Brasil, tendo como referência o período de julho de 1994 a setembro de 2000. Para tanto, os autores utilizaram de métodos de séries temporais, tais como: teste de raiz unitária proposto por Dickey e Fuller (ADF), teste de cointegração de Johansen, modelo vetorial de correção de erro e função de resposta de impulso. Após a realização dos testes, foi encontrada a presença de um vetor de cointegração, o que confirma a existência de relação de longo prazo entre as variáveis analisadas. Segundo os autores, esse resultado, de um lado, capta o próprio processo de globalização das economias, onde há maior inter-relação entre os preços domésticos e externos e, também, o processo de abertura da economia brasileira, iniciado em 1990, que foi intensificado pós-plano real.

Lovadine e Bacchi (2005), valendo-se das médias semanais de preços para o período de janeiro de 1999 a janeiro de 2004, tentaram identificar relações causais e estimar as elasticidades de transmissão entre os seguintes pares de preços: preço interno e internacional de soja em grão; preço interno e internacional de farelo de soja e preço interno e internacional de óleo de soja. Os métodos usados foram o teste de raiz unitária, teste de cointegração, teste de causalidade de Granger utilizando correlação cruzada com variáveis pré-filtradas com modelos auto-regressivos e estimação da elasticidade de transmissão de preços. O teste de cointegração apontou indícios de relações de longo prazo entre os preços interno e externo do grão e entre preços interno e externo do farelo. Não se observou, contudo, relação de longo prazo estatisticamente significativa entre os preços interno e externo do óleo.

Como é possível perceber, embora Margarido e Fernandes (2001) e Lovadine e Bacchi (2005) trabalhem com períodos distintos, os primeiros de 1994 a 2000 e os segundos, de 1999 a 2004, os resultados apontam que há, de fato, uma relação de longo prazo entre as variáveis analisadas e, mais que isso, que há uma aceleração no processo de transmissão de preços. Como melhor explicam:

[...] comparativamente a outros estudos de causalidade realizados para a década de 80 e início dos anos 90, em que a transmissão dos preços ocorria em questão de meses, esse trabalho mostra que houve um aceleramento da velocidade de transmissão entre os preços. Tal fato pode ser atribuído à 
p. 5 - Relação de longo prazo entre os preços da carne bovina: evidências empíricas.

facilidade de acesso à informação proporcionado pela internet, principalmente a partir de meados dos anos 90. (Lovadine e Bacchi, 2005, p. 6)

Em estudo com metodologia semelhante, Barbosa et al. (2002) analisaram a elasticidade da transmissão de preços no mercado brasileiro de algodão entre o período de janeiro de 1985 até dezembro de 2000. O objetivo deste estudo era estimar a elasticidade da transmissão de preços no mercado de algodão, considerando os preços internacionais desta commodity verificar a existência de relacionamento de longo prazo entre os preços internacionais e domésticos do algodão. Tanto o estudo em pauta como os estudos anteriormente citados tem como hipótese a validação ou não da Lei do Preço Único, que está diretamente associado à arbitragem internacional dos preços e tem como premissa a ideia de que: "em mercados concorrenciais livres de custos de transporte e de barreiras oficiais ao comércio (como as tarifas), bens idênticos vendidos em países diferentes devem ser vendidos pelo mesmo preço, quando seus preços são indicados em termos da mesma moeda". Com o intuito de determinar a ordem de integração das variáveis, os autores utilizaram o teste de raiz unitária de Dickey-Fuller Aumentado (ADF) e o teste de cointegração de Johansen ${ }^{1}$. Os resultados obtidos mostram que há relacionamento de longo prazo entre os preços do algodão no mercado doméstico brasileiro e internacional.

Contudo, conforme advertem os autores, mesmo sendo estas variáveis cointegradas, ainda assim, a elasticidade de transmissão de preços é menor que a unidade (inelástica), o que significa dizer que variações nos preços internacionais do preço do algodão em pluma não são transmitidos nas mesmas proporções para os preços praticados no Brasil, no longo prazo, o que inviabiliza a Lei do Preço Único (BARBOSA et al., 2002).

Há, também, estudos direcionados à análise dos preços do boi gordo e da carne bovina, este último, objeto de estudo deste trabalho. Zilli et al. (2008), em estudo recente, tentaram identificar a relação de causalidade entre preços do boi gordo em praças nas Regiões Sudeste e Centro-Oeste do Brasil. Para tanto, os autores utilizaram dados de preços diários de boi gordo (Reais por arroba $(15 \mathrm{~kg}): \mathrm{R} \$ / @)$ das praças de Campo Grande (MS), Cuiabá (MT), Goiânia (GO) e Triângulo Mineiro (MG), referentes ao período de 02/01/2002 a 28/12/2007. Como método de análise os autores utilizaram o teste de cointegração de Johansen e a causalidade no sentido de Granger, identificando, assim, que todas as séries analisadas eram não estacionárias, o que exigiu a realização do teste de cointegração, a partir do qual se verificou a existência de relação de equilíbrio de longo prazo entre todas as praças. Segundo os autores, os resultados condizem com a interpretação que se faz do atual mercado de boi gordo brasileiro, cujos preços são rapidamente divulgados, refletindo na formação de preços de todas as praças. Além disso, os autores apontam que o mercado do boi gordo é um mercado bastante

\footnotetext{
${ }^{1}$ DICKEY, D.A.; FULLER, W.A. Distribuition on the estimator for auto-regressive time series with a unit root. Journal of the American Statistical Association, Alexandria, v. 74, p. 427-431, 1979.

JOHANSEN, S. Statistical analysis of cointegracion vectors. Journals of Economic Dynamics and Control, Boston, v.12, p. 231-254, 1988.
} 
integrado, no qual o produtor de cada região busca sempre obter informações sobre preços tanto na praça próxima quanto na BM\&F.

Lobo e Silva Neto (2011) analisaram o processo de transmissão de preços do produtor ao varejo no setor de carne bovina em Goiás, usando, as séries mensais de preços de janeiro de 1995 a dezembro de 2010. O processo de transmissão de preços do produtor ao varejo foi detectado a partir dos testes de raiz unitária de Dickey-Fuller Aumentado (ADF), do critério de informação de Schwartz e de análise de regressão. Conforme apontam os autores, os resultados do estudo indicam que um choque exógeno de $1 \%$ nos preços ao varejo afetam os preços ao produtor contemporaneamente em $0,91 \%$, ou seja, um aumento em $1 \%$ nos preços ao varejo elevam os preços ao produtor em $0,91 \%$ e um choque exógeno de $1 \%$ nos preços ao produtor elevam os do varejo em 0,93\%. A partir destas análises de elasticidade preço, os autores concluem que em Goiás, não há, entre produtor e varejista, um agente dominante quanto à determinação dos preços ou que, pelo menos, os dois agentes reagem, significativamente, a choques exógenos provocados pela outra parte.

\section{ABORDAGEM METODOLÓGICA E DADOS}

Para a realização dos testes empíricos foram utilizadas três séries de dados:

- a média do preço a vista do bezerro nelore (por cabeça - 8 a 12 meses) no mercado da região de Goiânia;

- a média do preço a vista do boi gordo no mercado da região de Goiânia; e

- a média do preço da carne no varejo, também para o mercado de Goiânia.

Os dados apresentam fontes distintas, conforme Quadro 1. Todas as séries foram convertidas em uma mesma unidade de medida, obtendo-se, assim, o preço médio por quilo. Admitiu-se, para tanto, o peso médio do bezerro de 198 quilos, segundo metodologia adotada pelo CEPEA. Depois de padronizada a unidade de medida, foi preciso deflacionar os dados, tendo como referência, dezembro de 2011, último período da série. Foi usado o Índice Geral de Preços - Disponibilidade Interna - IGP-DI da Fundação Getúlio Vargas.

Quadro 1 - Fontes e descrição das variáveis que compõe o modelo teórico, dados mensais: jan/2001 a dez/2011

\begin{tabular}{|l|l|c|}
\hline \multicolumn{1}{|c|}{ Variável } & \multicolumn{1}{|c|}{ Descrição da Variável } & Fonte \\
\hline Preço do Bezerro (BZ) & $\begin{array}{l}\text { Preço do bezerro, em valores de dezembro de 2011, } \\
\text { em R\$/Kg }\end{array}$ & CEPEA \\
\hline Preço ao Produtor (PP) & $\begin{array}{l}\text { Preço do Boi Gordo, em valores de dezembro de 2011, } \\
\text { em R\$/Kg }\end{array}$ & CEPEA \\
\hline Preço no Varejo (PV) & $\begin{array}{l}\text { Preço médio do Kg da carne, em reais (R\$), em valores } \\
\text { de dezembro de 2011. }\end{array}$ & DIEESE \\
\hline
\end{tabular}

Fonte: Elaborado pelos autores.

Nota: Em todas as variáveis foi aplicado logaritmo. 
p. 7 - Relação de longo prazo entre os preços da carne bovina: evidências empíricas.

A Figura 1 mostra os índices dos preços. Nota-se que todas as séries sofrem fortes quedas entre 2002 e meados de 2006 e após esse período há uma tendência de recuperação dos preços, no entanto, somente os preços ao varejo são maiores que os valores do início do período analisado. Com isso, fica claro que os preços da carne bovina em Goiás têm ficado estagnados em níveis pouco atrativos aos agentes dessa cadeia.

Para o uso da metodologia VAR com identificação pelo procedimento de Bernanke (VAR-estrutural) torna-se essencial o uso de um modelo econômico que dê suporte à especificação do modelo estatístico. O modelo teórico desenvolvido é utilizado para estabelecer as restrições a serem impostas na matriz de relações contemporâneas entre as variáveis. Essas restrições são necessárias para a identificação do modelo na sua forma estrutural a partir do ajustamento do modelo na forma reduzida (Enders, 2004).

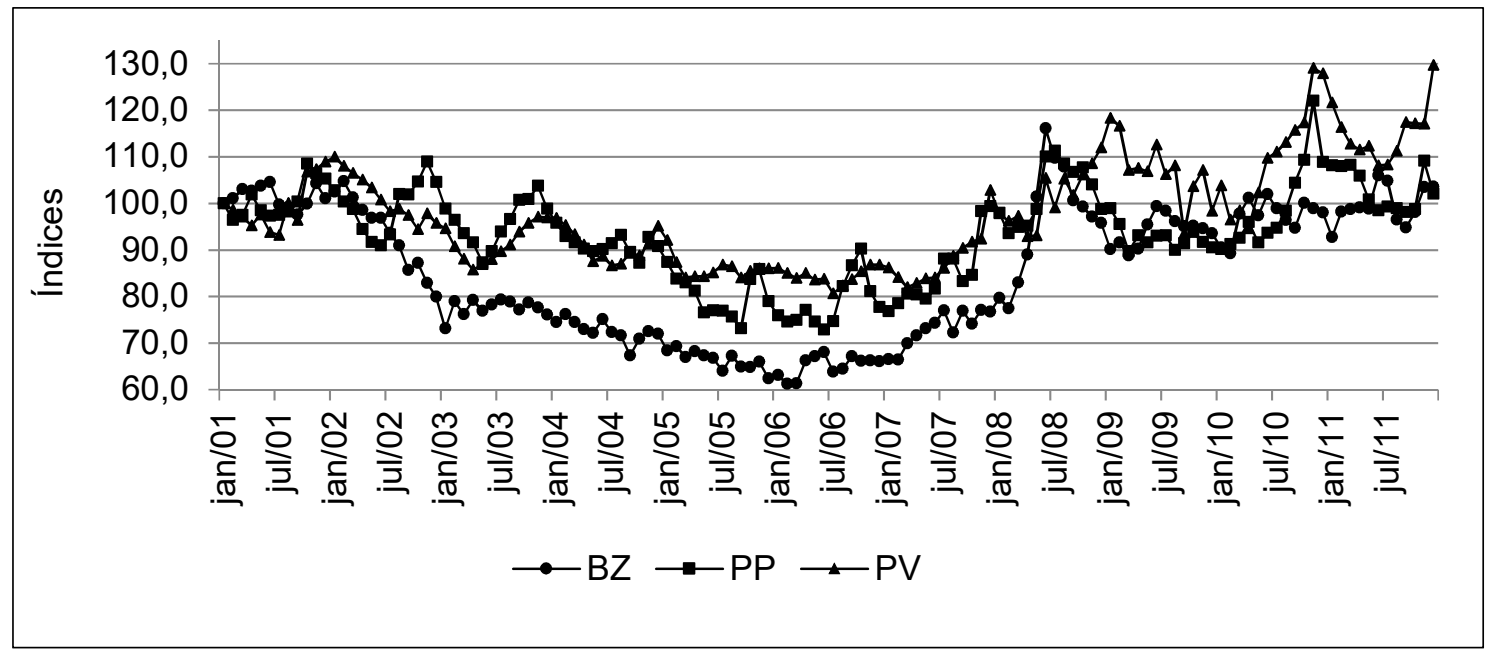

Figura 1 - Índices de preços do bezerro, boi gordo e varejo da carne bovina em Goiás Fonte: Elaborado pelos autores com base nas fontes explicitadas no Quadro 1.

Nas séries usadas neste estudo, sabe-se que há uma hierarquia dada pela própria lógica da cadeia produtiva da carne ( $\mathrm{BZ} \Rightarrow \mathrm{PP} \Rightarrow \mathrm{PV}$ ). Não se sabia, contudo, o quanto, na série, os valores de uma e outra variável podiam ser explicados pelos valores defasados dela própria e das outras variáveis.

Dadas estas relações, torna-se possível construir uma matriz de relações contemporâneas e, a partir dela se especificar um modelo econométrico ajustado utilizando a metodologia de Auto-Regressão Vetorial com identificação pelo processo de Bernanke. A Tabela 1 apresenta a matriz de relações contemporâneas.

Tabela 1 - Matriz de relações contemporâneas

\begin{tabular}{l|l|l|c}
\hline \multicolumn{2}{l|}{ BZ } & PP & PV \\
\hline BZ & 1 & $1^{\mathrm{A} 1}$ & 0 \\
PP & 0 & 1 & $1^{\mathrm{B} 1}$ \\
PV & 0 & 0 & 1 \\
\hline
\end{tabular}

Fonte: Elaborado pelos autores. 
Outra questão teórica a ser explorada diz respeito à estacionariedade ou não das séries temporais utilizadas no modelo. Séries não estacionárias devido à tendência estocásticas (raiz unitária) tornam-se estacionárias após diferenciação (ENDERS, 2004). No entanto, se as séries forem integradas e co-integradas, há necessidade de conciliar relações de curto e longo prazos através do uso de modelos de correção de erro (MADDALA, 2003).

Os testes de raiz unitária foram feitos com base no desenvolvido Elliot, Rothenberg e Stock (1996) conhecido como Dickey-Fuller Generalized Least Square - DFGLS, indicado para ser usado quando o número de observações da série temporal é pequeno e quando existem termos deterministas não observados no processo gerador da série. Quanto à escolha do número de defasagens, foi usado um critério proposto por Ng e Perron (2001), denominado Critério Modificado de Akaike - MAIC, conforme recomenda a literatura.

O modelo econométrico definido para a análise da relação de longo prazo entre os preços na cadeia de carne bovina em Goiás foi ajustado utilizando um modelo de Autoregressão Vetorial. O software econométrico usado para a realização dos testes foi o Regression Analysis of Time Series - RATS 6.2, no seu complemento Cointegration Analysis of Time Series - CATS.

\section{RESULTADOS E DISCUSSÕES}

Na Tabela 2 estão os resultados dos testes de raiz unitária para as variáveis em análise. Como demonstrado anteriormente, o teste usado foi o proposto por Eliot, Rorhemberg e Stock (1996), também chamado de Dickey-Fuller Generalized Least Square - DF-GLS. Quanto ao número de defasagens das variáveis, foi usado o critério modificado de Akaike (MAIC), e os resultados foram os mesmos para os dois modelos. A ordem de cada um encontra-se especificada na segunda coluna da tabela.

Os resultados indicam que todas as séries são integradas de ordem 1 - I (1) ao nível de significância de 0,01 de probabilidade tanto no modelo com constante e tendencia como no com apenas constante.

Tabela 2 - Resultado dos testes de raiz unitária de Elliot-Rothenberg-Stock (DF-GLS)

\begin{tabular}{llcc}
\hline \multirow{2}{*}{ Variável } & & Modelo 1 & Modelo 2 \\
\cline { 3 - 4 } & & Estatística DF-GLS & Estatística DF-GLS \\
\hline Preço do Bezerro (BZ) & 8 & $-1,095$ & $-1,084$ \\
Preço ao Produtor (PP) & 8 & $-1,284$ & $-1,223$ \\
Preço no Varejo (PV) & 9 & $-0,758$ & $-0,276$ \\
1a Diferença Bezerro (DBZ) & 0 & -11.201 & -10.989 \\
1a Diferença Produtor (DPP) & 0 & -9.127 & -7.479 \\
1a Diferença Varejo (DPV) & 2 & -5.343 & -5.577 \\
\hline
\end{tabular}

Fonte: Elaborado pelos autores.

Modelo 1: na versão com constante e tendência (valores críticos em Eliot, Rothenberg e Stock (1996) (5\%= $-2,89 ; 1 \%=-3,48)$ ).

Modelo 2: na versão apenas com constante (valores críticos em Dickey e Fuller $(1979 ; 1981)(5 \%=-1,95$; $1 \%=-2,58))$. 
p. 9 - Relação de longo prazo entre os preços da carne bovina: evidências empíricas.

Diante de um contexto multivariado de análise e da possibilidade de identificação de mais de um vetor de cointegração, foi escolhido, para estimar as relações de longo prazo entre as variáveis, o teste de cointegração de Johansen (1988). Os modelos foram ajustados com drift, modelo com tendência que exibe tendência determinista no tempo.

Os resultados do teste, apresentados na Tabela 3, usando a estatística traço,indicam que não há relação de longo prazo entre as variáveis a um nível de significância de $5 \%$ de probabilidade, o que descarta a necessidade do uso de um Modelo de Autorregressão Vetorial com Correção de Erros - VEC (ENDERS, 2004). Sendo assim, estima-se um modelo VAR - Auto-Regressão Vetorial com as séries em primeira diferença

Tabela 3 - Resultados do teste de cointegração de Johansen

\begin{tabular}{cccc}
\hline Hipótese Alternativa $(\mathrm{HO})$ & Hipótese Alternativa $(\mathrm{H} 1)$ & Estatística Traço & Valores Críticos (5\%) \\
\hline $\mathrm{r} \leq 2$ & $\mathrm{r}=2$ & 1,007 & 9,142 \\
$\mathrm{r} \leq 1$ & $\mathrm{r}=1$ & 16,941 & 20,164 \\
$\mathrm{r} \leq 0$ & $\mathrm{r}=0$ & 34,987 & 35,070 \\
\hline
\end{tabular}

Fonte: Elaborado pelos autores.

Sobre os resultados os efeitos da matriz de relações contemporâneas (Tabela 4), em ambos os efeitos o sinal é positivo e estatisticamente significante. Um aumento de $1 \%$ nos preços do bezerro eleva contemporaneamente os preços do produtor em $0,16 \%$. No caso de uma alta de $1 \%$ nos preços do produtor, os preços do varejo sobem $0,11 \%$. Os sinais encontrados estão em acordo com o esperado no descrito na matriz de relações contemporâneas.

Tabela 4 - Estimativa para a matriz de relações contemporâneas

\begin{tabular}{|c|c|c|c|}
\hline \multicolumn{2}{|c|}{ Influência } & \multirow{2}{*}{$\begin{array}{c}\text { Coeficiente } \\
\text { Estimado }\end{array}$} & \multirow{2}{*}{$\begin{array}{c}\text { Nível de } \\
\text { Significância }\end{array}$} \\
\hline De & Sobre & & \\
\hline Preço do Bezerro (BZ) & Preço ao Produtor (PP) & 0,1592 & 0,0009 \\
\hline Preço ao Produtor (PP) & Preço no Varejo (PV) & 0,1146 & 0,0055 \\
\hline
\end{tabular}

Fonte: Elaborado pelos autores.

* Modelo sem constante e sem tendência.

Na Figura 2 são apresentados os efeitos de choques não antecipados 12 períodos à frente sobre os preços do bezerro. As elasticidades acumuladas são altas e no caso dos preços ao varejo, chegam a 13\% após 12 meses. O efeito sobre as demais variáveis também são significativos. Isso mostra que em tempos em que os preços estão pouco atrativos, as matrizes são abatidas o que pressiona os preços do bezerro - esse efeito é visto nessa análise. 


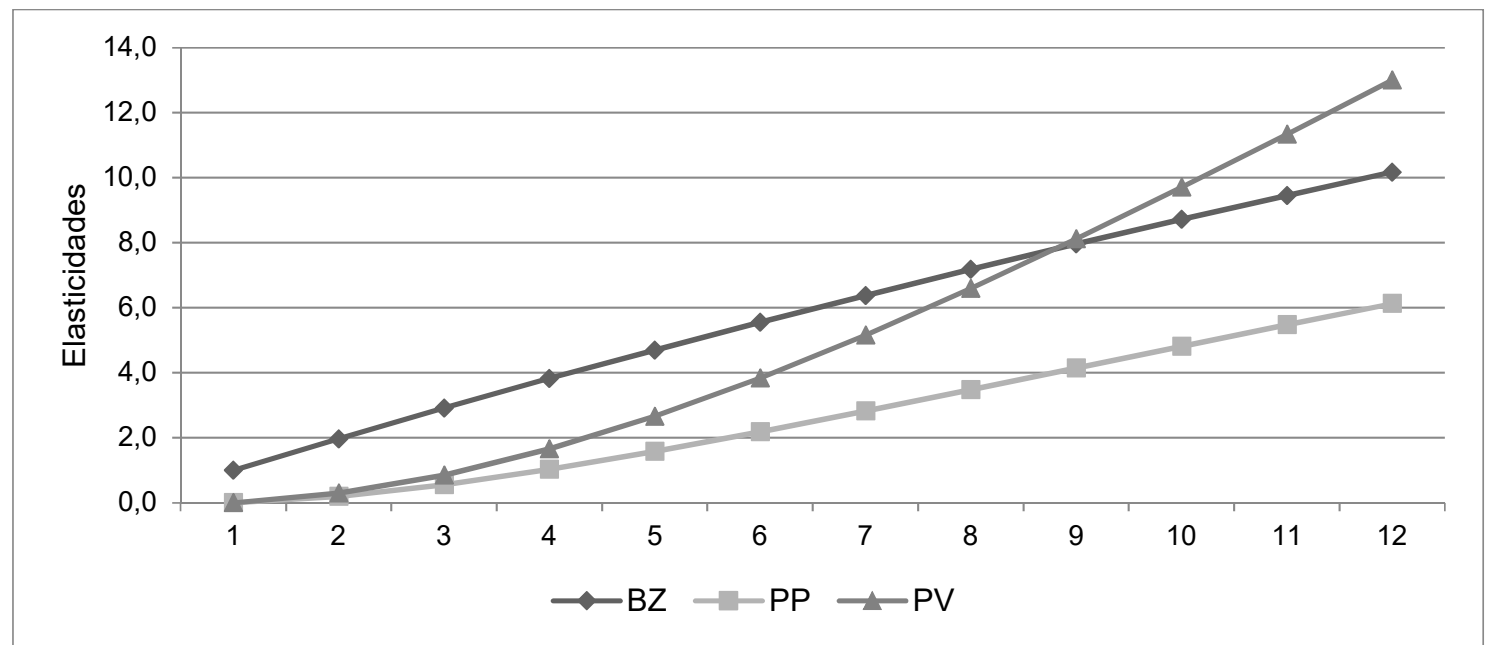

Figura 2 - Função de respostas acumuladas das variáveis a um choque nos preços do bezerro (BZ)

Fonte: Elaborado pelos autores.

Na Figura 3 são apresentados os efeitos sobre as séries de preços de um choque não antecipado nos preços ao produtor. Nota-se que os efeitos sobre os preços ao varejo (PV) e sobre a própria variável (PP) são elevados. Se os preços ao produtor aumentar $1 \%$, o efeito acumulado sobre os preços ao varejo e também sobre os preços ao produtor chegam a 5\% após 12 meses. A resposta dos preços ao varejo é de menor intensidade nos primeiros meses que a dos preços ao produtor.

O efeito de um choque exógeno nos preços do varejo sobre as séries do modelo está descrito na Figura 4. O Único efeito relevante é o sobre a própria variável que atinge após 12 meses uma elasticidade acumulada de 5\%. Esse resultado mostra que se a oferta de carne estiver normalizada e houver estoques, um choque de demanda provocará apenas a elevação nos preços do varejo, ou seja, os preços do bezerro e do boi gordo não irão gozar de alterações significativas.

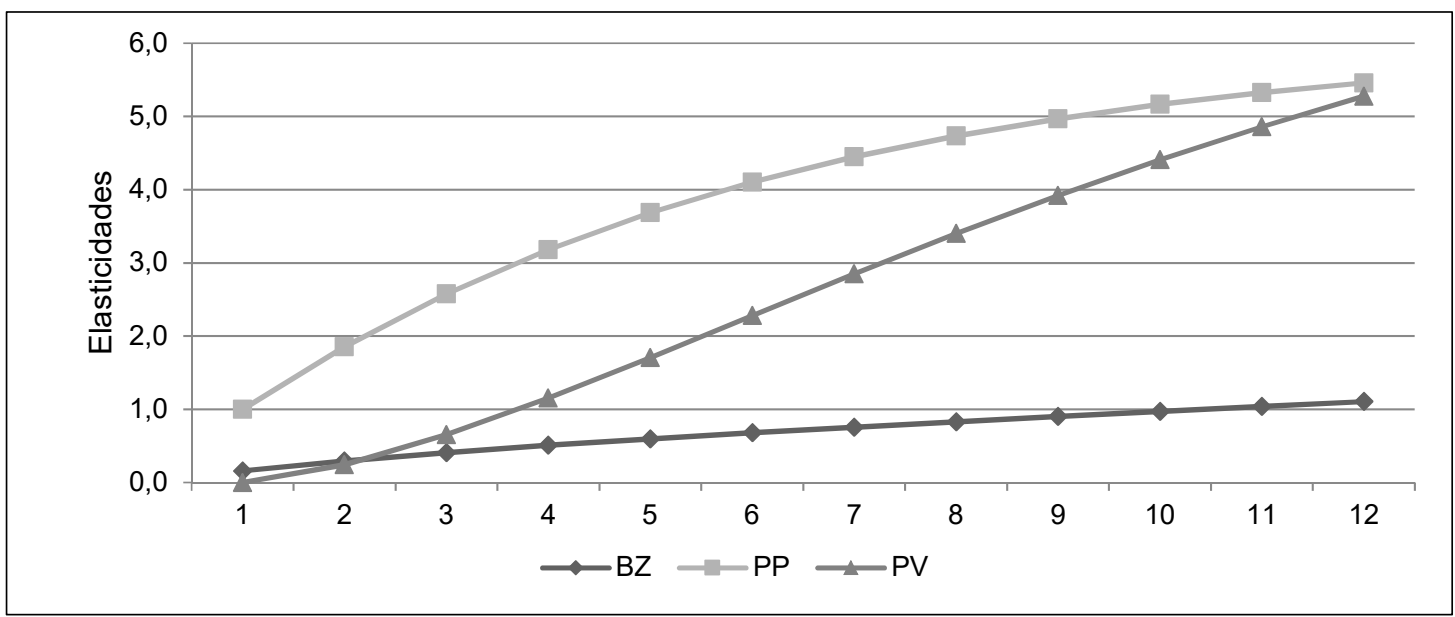

Figura 3 - Função de respostas acumuladas das variáveis a um choque nos preços do produtor (PP)

Fonte: Elaborado pelos autores. 
p. 11 - Relação de longo prazo entre os preços da carne bovina: evidências empíricas.

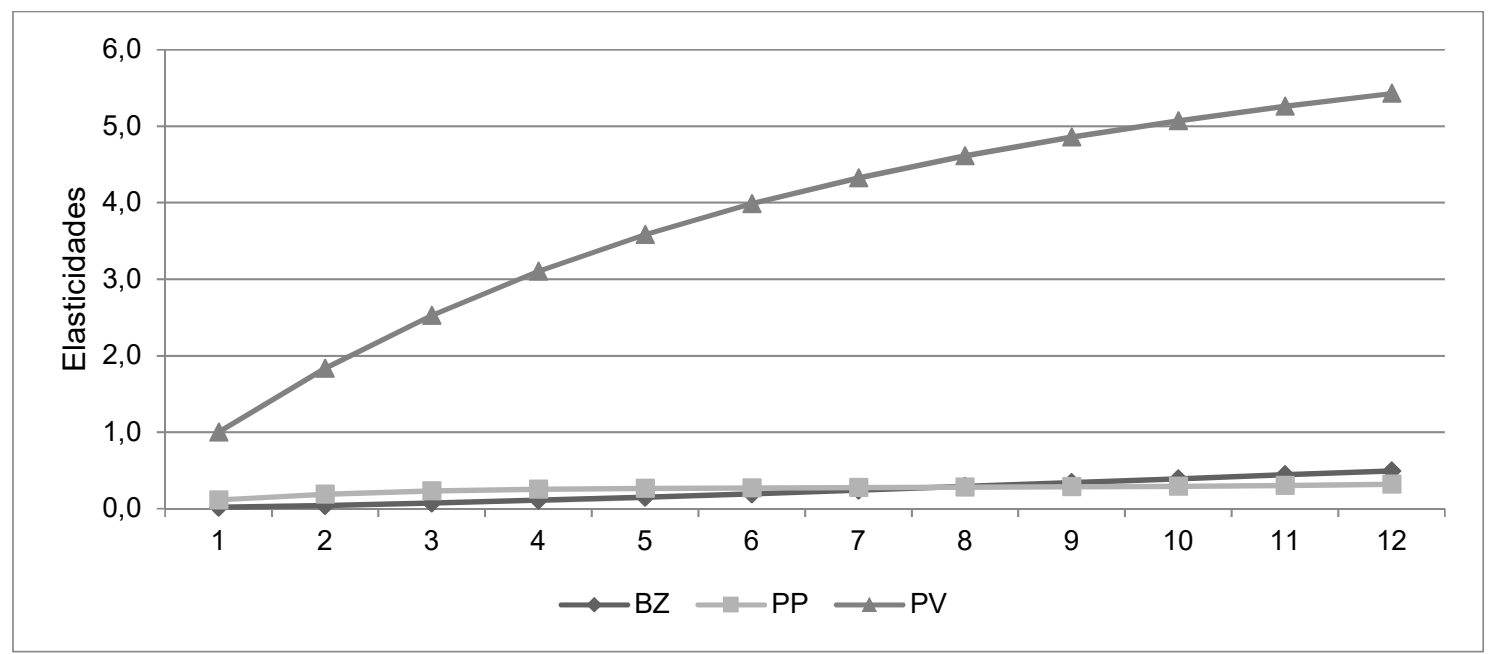

Figura 4 - Função de respostas acumuladas das variáveis a um choque nos preços do varejo (PV)

Fonte: Elaborado pelos autores.

Na Figura 5, pode-se observar que os preços do bezerro é que explica em grande parte ele mesmo. Sobre os fundamentos, a Figura 6 revela que as previsões não captaram as variações na série de preços do bezerro. Baseando-se na Figura 7 conclui-se que em $90 \%$ das vezes, os fundamentos (séries de preços do modelo) explicam mais que $60 \%$ das variações nos preços do bezerro.

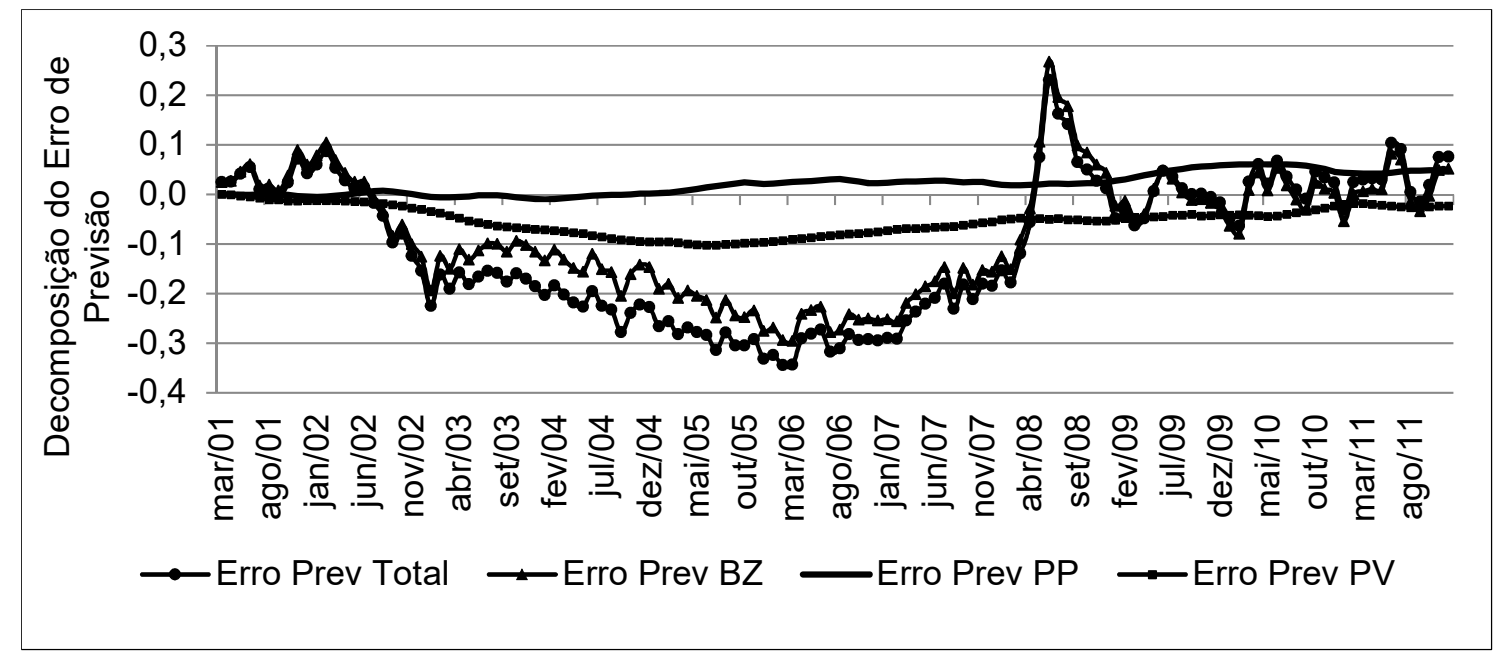

Figura 5 - Decomposição histórica do erro total de previsão dos preços do bezerro em percentagens atribuídas a cada variável do sistema

Fonte: Elaborado pelos autores. 


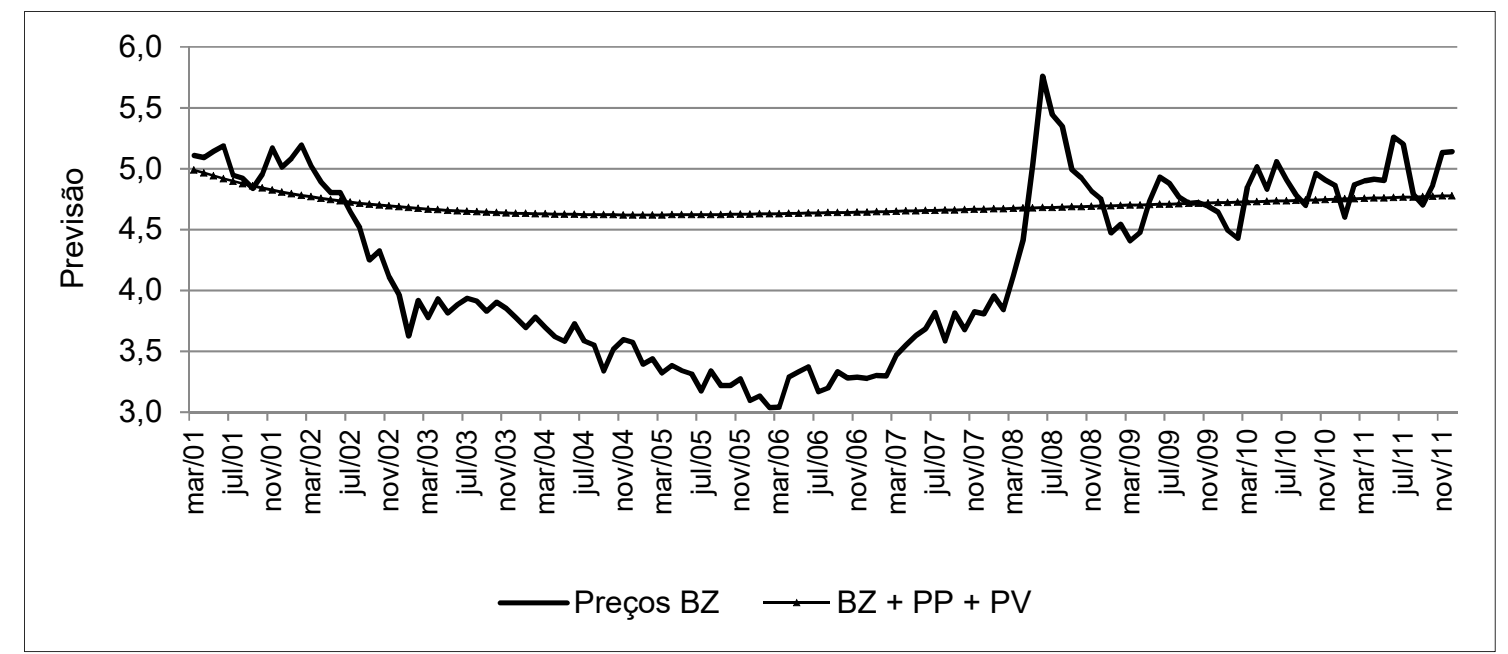

Figura 6 - Previsões dos preços do bezerro baseadas no conjunto das variáveis explicativas do modelo e série efetiva dos preços do bezerro Fonte: Elaborado pelos autores.

Na Figura 8, pode-se observar que o preço do produtor é explicado, em grande parte, pelas três variáveis do sistema. Na Figura 9 é possível notar que os fundamentos (preços do bezerro, produtor e varejo) não explicam de forma satisfatória os preços do produtor, em especial, no período entre setembro de 2003 a abril de 2008. Baseando-se na Figura 10 conclui-se que em 90\% das vezes, os fundamentos (séries de preços do modelo) explicam mais que $60 \%$ das variações nos preços do produtor, assim como na variável anterior.

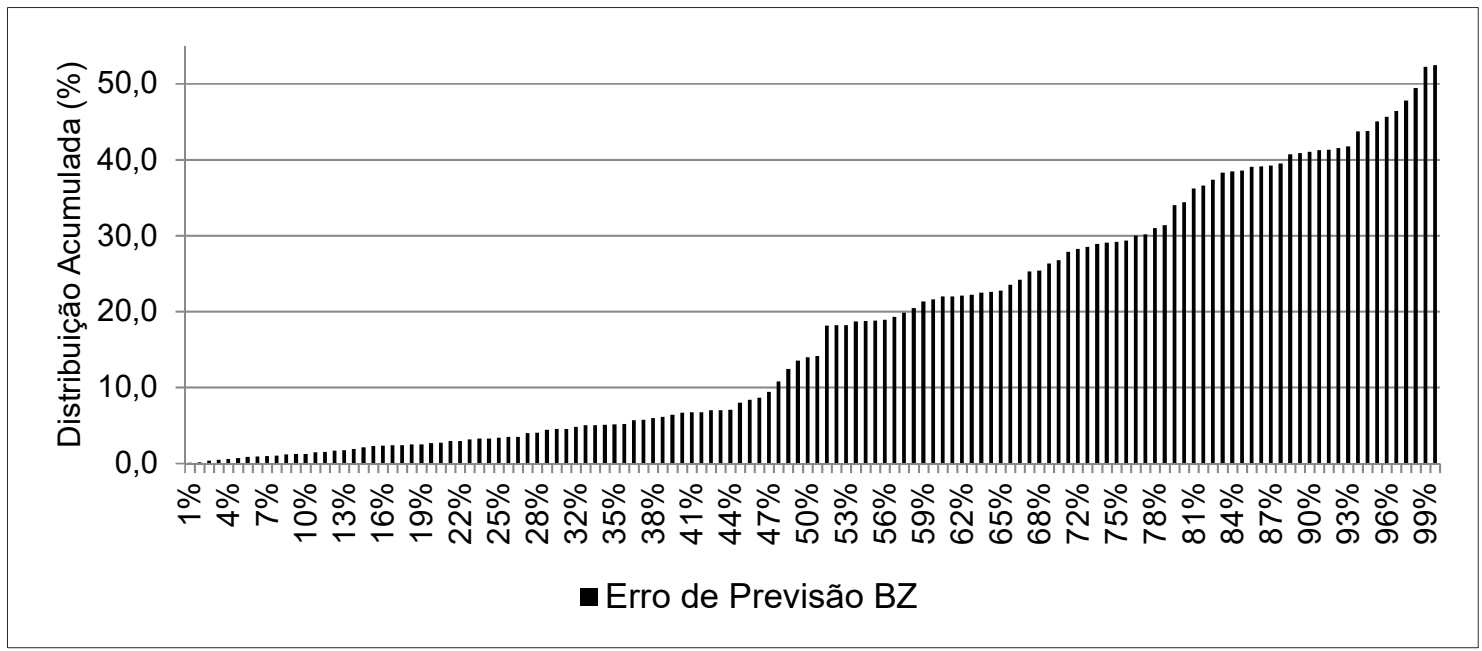

Figura 7 - Erros de previsão ordenados para os preços do bezerro Fonte: Elaborado pelos autores. 


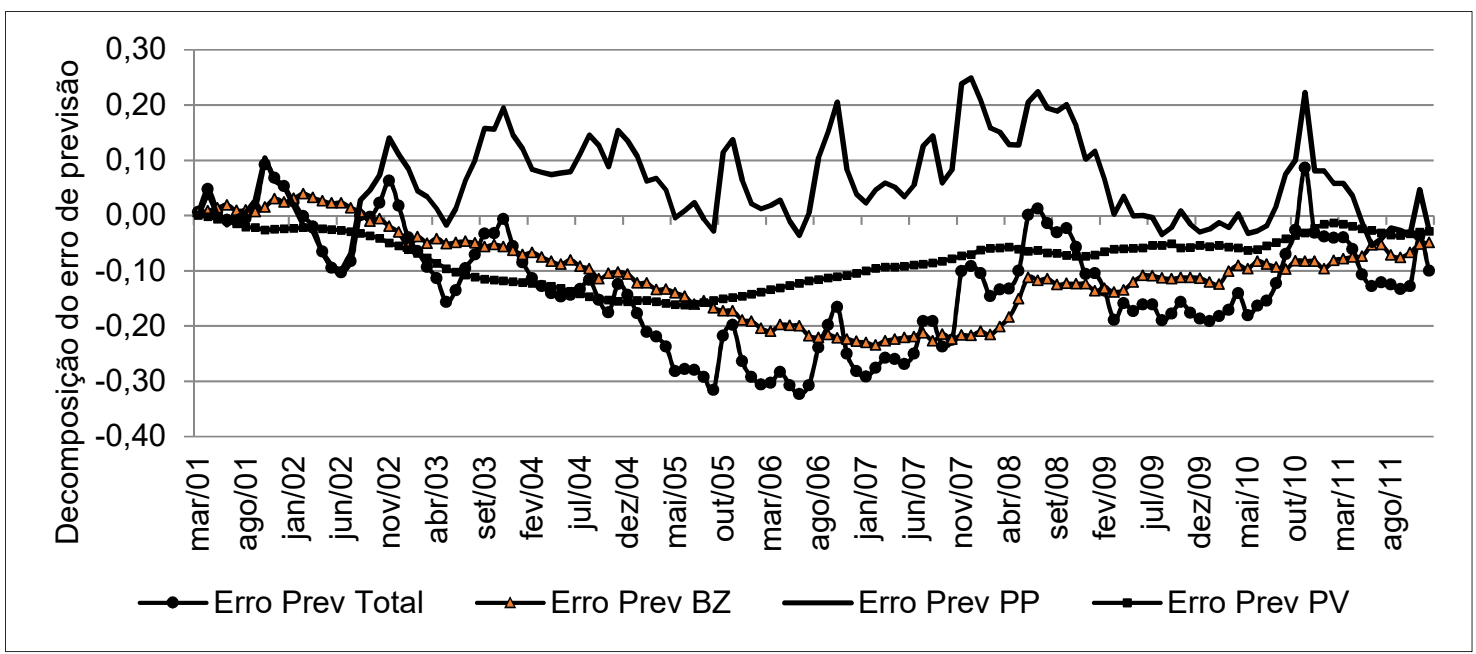

Figura 8 - Decomposição histórica do erro total de previsão dos preços do produtor em percentagens atribuídas a cada variável do sistema Fonte: Elaborado pelos autores.

Na Figura 11, pode-se observar que o erro total de previsão dos preços do varejo é explicado pelas três variáveis do sistema. Quanto às previsões dos preços do varejo, assim como nas outras duas séries de preços analisadas anteriormente, não foram bem explicadas pelos fundamentos (Figura 12). Quanto aos erros de previsão (Figura 13), verifica-se que em $90 \%$ das vezes, os fundamentos (séries de preços do modelo) explicam mais que $60 \%$ das variações nos preços do varejo.

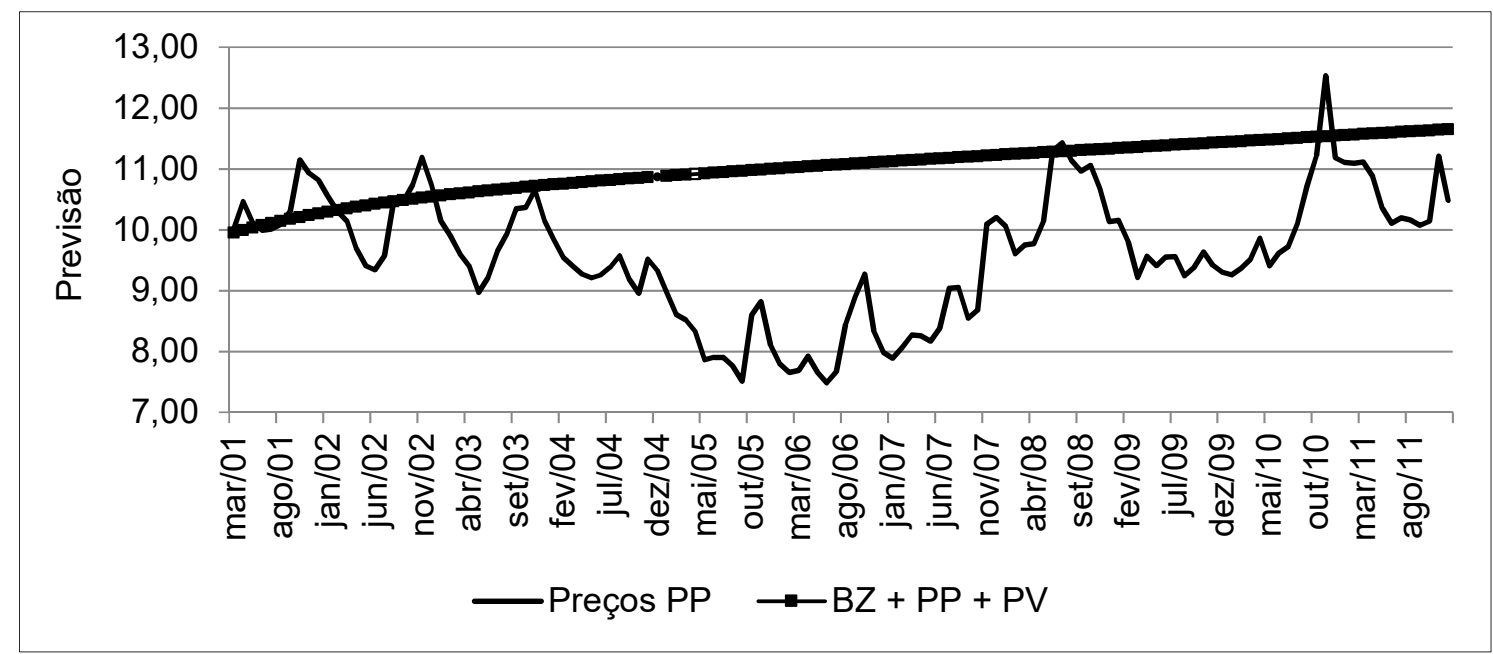

Figura 9 - Previsões dos preços do produtor baseadas no conjunto das variáveis explicativas do modelo e série efetiva dos preços do produtor Fonte: Elaborado pelos autores. 


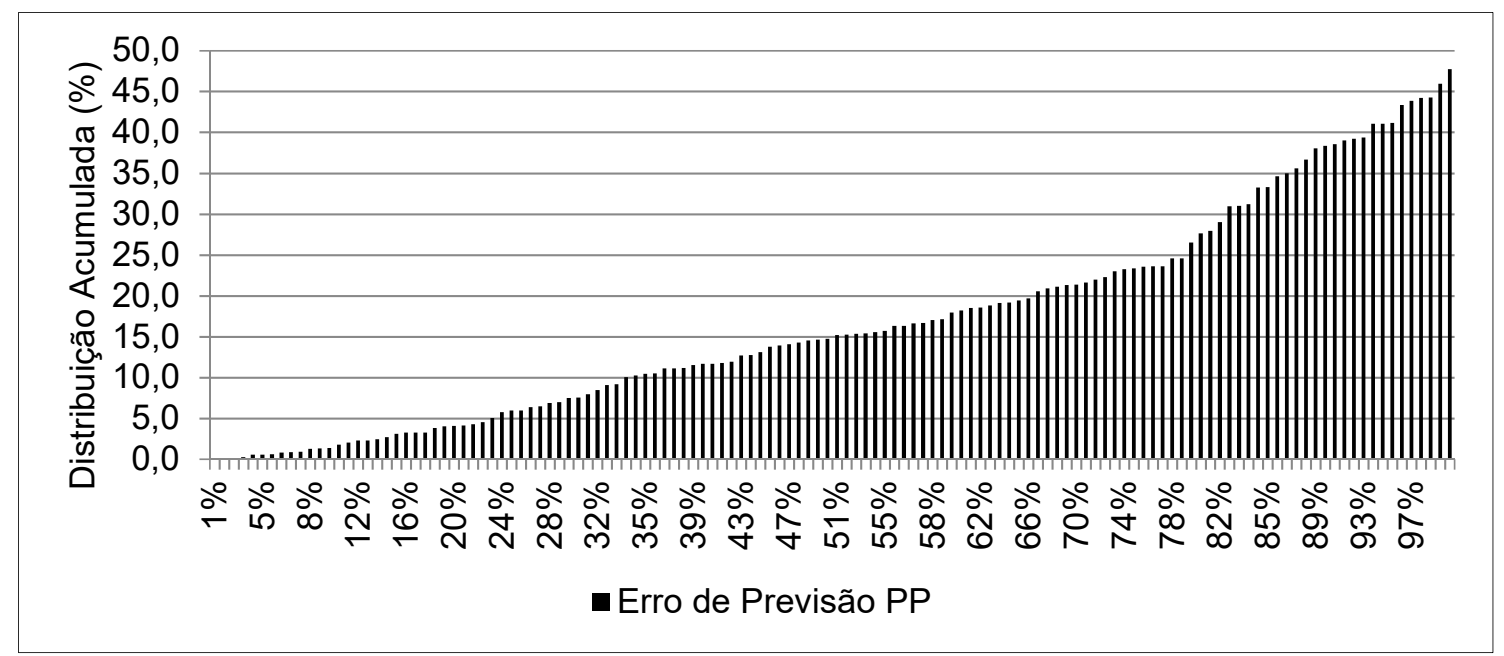

Figura 10 - Erros de previsão ordenados para os preços do produtor Fonte: Elaborado pelos autores.

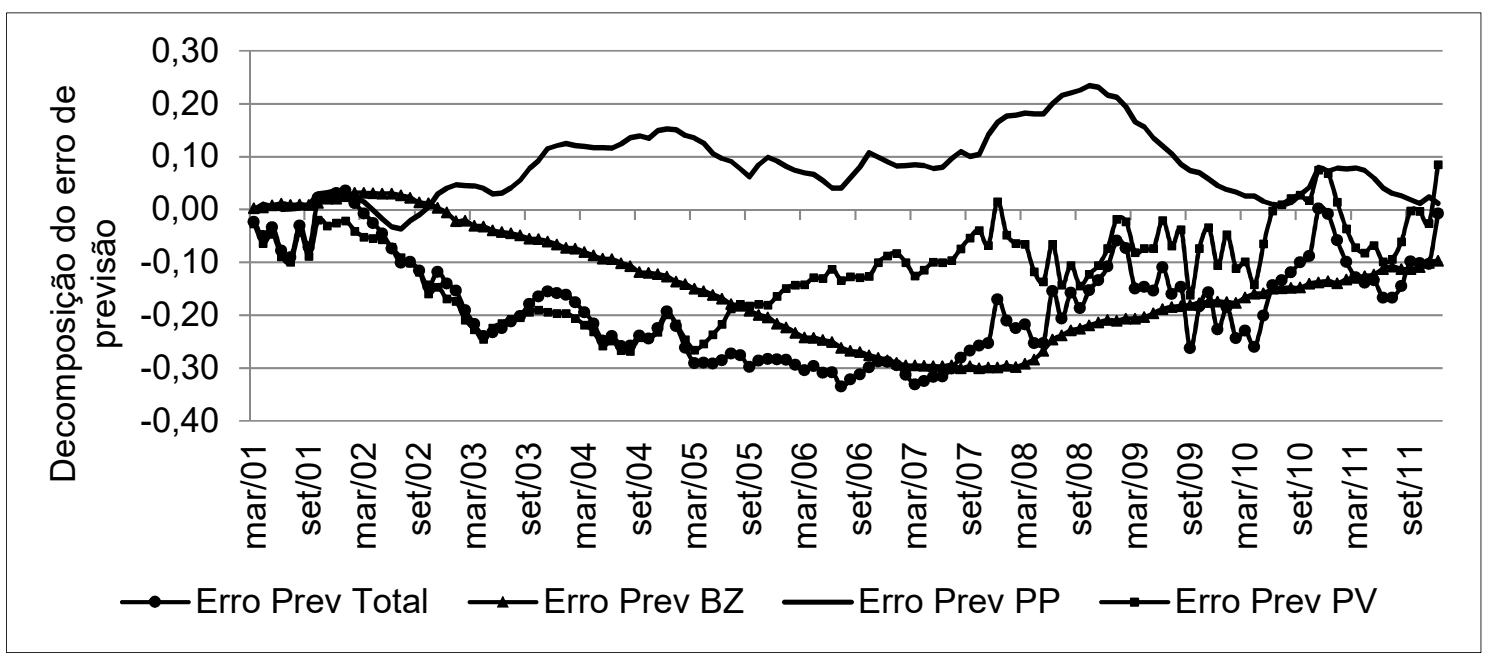

Figura 11 - Decomposição histórica do erro total de previsão dos preços do varejo em percentagens atribuídas a cada variável do sistema

Fonte: Elaborado pelos autores. 
p. 15 - Relação de longo prazo entre os preços da carne bovina: evidências empíricas.

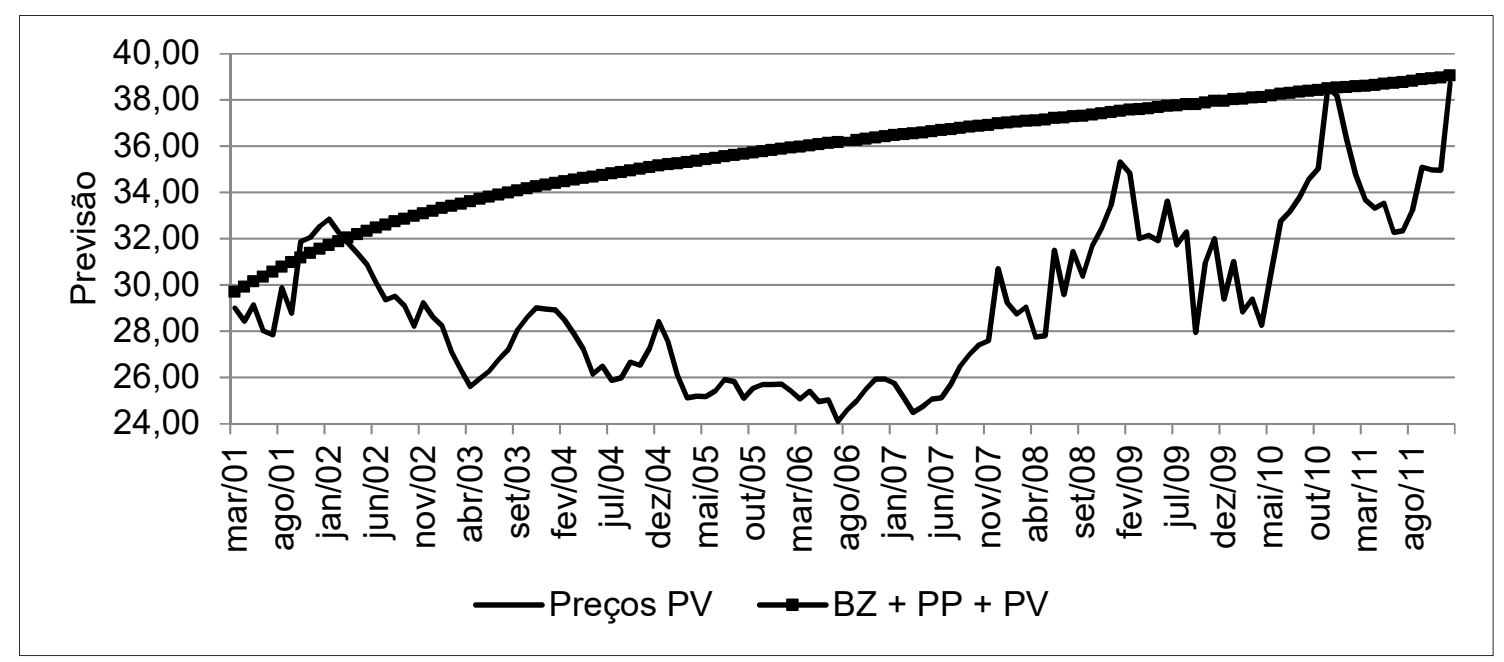

Figura 12 - Previsões dos preços do varejo baseadas no conjunto das variáveis explicativas do modelo e série efetiva dos preços do varejo Fonte: Elaborado pelos autores.

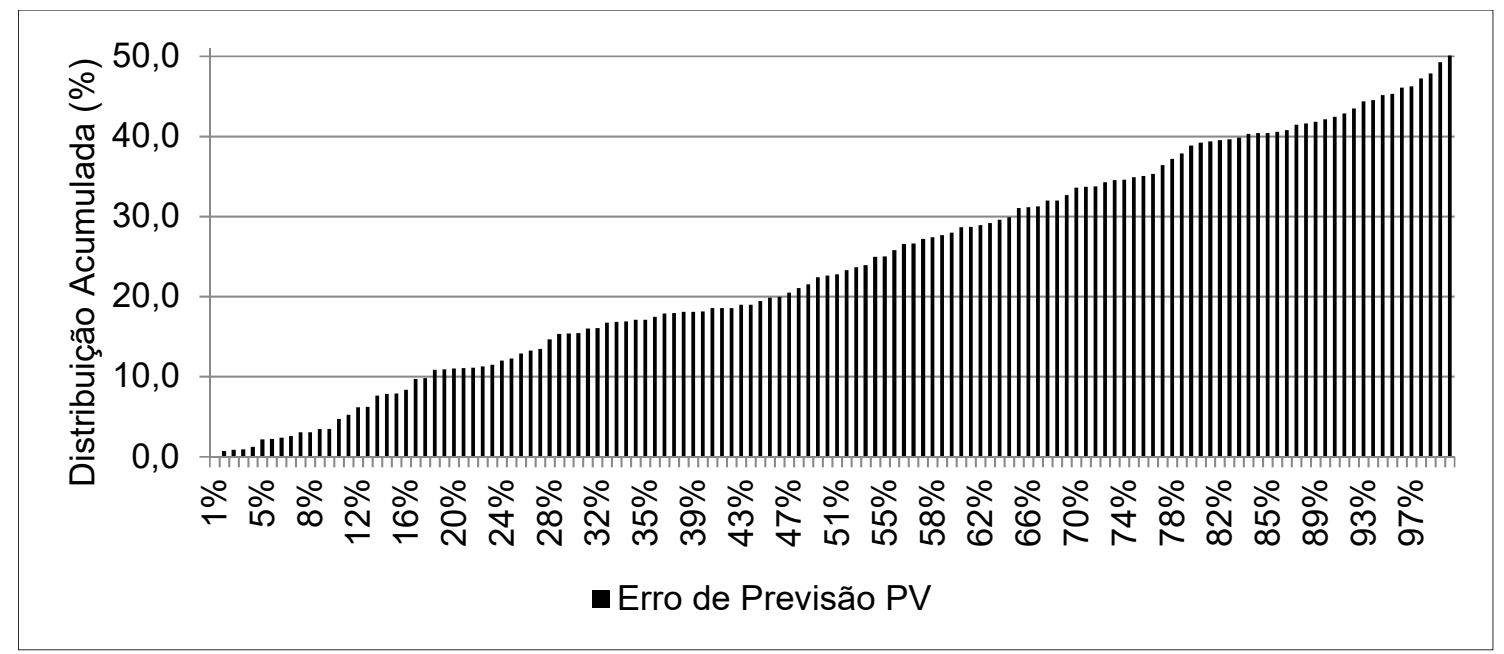

Figura 13 - Erros de previsão ordenados para os preços do varejo Fonte: Elaborado pelos autores.

Os resultados observados nas Figuras 4 e 11 a 13, mostram que os preços ao varejo não são afetados pelos demais. Isso revela que em Goiás pode estar ocorrendo o mesmo que já foi apontado por Urso (2007), Macedo (2009) e Silva Neto e Parré (2012) a nível nacional:há fortes indicios de que cadeia de carne bovina possui uma baixa coordenação entre seus agentes e que há assimetria nas relações comerciais entre os agentes da cadeia e que também há indícios de poder de mercado, onde as reduções nos preços são apropriadas pelos agentes que detém maior poder. A existência de assimetria na transmissão de preços apontada por Silva Neto e Parré (2012) estimula a baixa coordenação e ganhos de curto prazo, oriundo das oscilações do ciclo de preços, e que isso torna o relacionamento entre os agentes, caracterizado por ações oportunistas (Macedo 2009). 


\section{CONSIDERAÇÕES FINAIS}

Os resultados alcançados na análise proposta sugerem que não há relação de longo prazo entre os preços do bezerro, boi gordo e varejo da carne bovina em Goiás. Além disso, choques exógenos nos preços ao varejo não afetam os preços dos agentes anteriores na cadeia. Com isso, choques nesse segmento não são transmitidos nem aos produtores de boi gordo nem de bezerro. Logo, decisões de curto prazo, como a de confinar o gado na tentativa de gozar de uma alta de preço pontual na demanda podem não se reflitir em elevação nos preços da arroba do boi gordo. Isso revela um indício de que o maior nível de informações do agente que está mais próximo do consumidor (varejista), aliado ao poder de mercado existente, pode estar proporcionando a apropriação da elevação nos preços em nível de varejo provocados por um choque não antecipado na demanda.

A importância desses resultados para o estado de Goiás é muito grande, pois, poucas pesquisas têm sido conduzidas sobre esse importante segmento da economia goiana. A metodologia adotada mostrou-se adequada para o objetivo proposto. No entanto, outros estudos podem se apropriar desses resultados e avançar ainda mais: inserir o preço do boi magro na análise e a de outros produtos considerados substitutos da carne bovina, como o frango e o suíno. Com esses novos resultados, políticas públicas devem ser fomentadas na tentativa de garantir o bem estar do consumidor e em manter o crescimento da pecuária bovina em Goiás.

\section{REFERÊNCIAS BIBLIOGRÁFICAS}

ALENCAR, Leonardo S, de. Raízes unitárias e cointegração: uma introdução. Boletim do Banco Central do Brasil, Brasília, p. 171-210, Abr. 1998.

BARBOSA, Z. B; MARGARIDO, M. A.; JÚNIOR, S. N. Análise da elasticidade de transmissão de preços no mercado brasileiro de algodão. Nova Economia, Belo Horizonte, v. 12(2) p. 79 -108, julho/dezembro, 2002.

BERNANKE, B.S. Alternative explanations of money-income correlation. CarnegieRochester Conference Series on Public Policy, Rochester, v. 25, p. 49 - 100, 1986.

Centro de Estudos Avançados em Economia Aplicada - CEPEA, (2012). Disponível em: <www.cepea.esalq.usp.br/>acesso em: 15abril. 2012.

DEPARTAMENTO INTERSINDICAL DE ESTATÍSTICAS E ESTUDOS SOCIOECONÔMICOS DIEESE. Disponível em: <http://www.dieese.org.br/> Acesso em: 18 abr. 2012.

Elliot, G., Rothenberg, T. J. Stock, J. H. Efficient tests for an autoregressive unit root, Econometrica 64, 813-836, 1996.

ENDERS, W. Applied econometric time series. New York : John Wiley \& Sons, 2004.

FEDERAÇAO DA AGRICULTURA E PECUARIA DE GOIAS (FAEG). Disponível em: <http://www.faeg.go.gov.br> acesso em: 15 de março. 2012.

Instituto Brasileiro de Geografia e Estatística - IBGE. Disponível em: <http://www.ibge.gov.br> Acesso em:15 de março. 2011. 
p. 17 - Relação de longo prazo entre os preços da carne bovina: evidências empíricas.

LOBO, O. A.; NETO, W. A. S. Transmissão de preços entre o produtor e o varejo: experiências empíricas para o setor da carne bovina em Goiás. Conjuntura Econômica Goiana, no 19, p- 56 -63. Dez, 2011.

LOVADINE, D. ; BACCHI, M. R. P. . Causalidade e transmissão de preços entre mercado interno e internacional para produtos do complexo soja. In: Congresso Nacional de Economia e Sociologia Rural, 2005, Ribeirão Preto. Sociedade Brasileira de Economia e Sociologia Rural, 2005.

MACEDO, L.O.B. (2009) Perfil de Governança e a Coordenação de Alianças Estratégicas do Sistema Agroindustrial da Carne Bovina Brasileira. Tese (Doutorado) p.203. Universidade de São Paulo - Escola Superior de Agricultura 'Luiz de Queiroz', Piracicaba.

MADDALA, G.G. Introdução à econometria. 3.ed. Rio de Janeiro: LTC, 345 p, 2003.

MARGARIDO, M. A.; FERNANDES, J. M. Análise da formação de preços no mercado internacional de soja: o caso Brasil. Textos pata Discussão 06/01. Programa de Estudos Pós-Graduados em Economia Política/PUCSP, 2001.

MINISTÉRIO DA AGRICULTURA E PECUÁRIA - MAPA (2012). Disponível em: http://www.agricultura.gov.br/acesso em: 15 de março. 2012.

$\mathrm{Ng}$, S. Perron, P. (2001), 'Lag length selection and the construction of unit root tests with good size and power', Econometrica 69, 1519-1554.

SEPLAN, Secretaria de Planejamento do Estado de Goiás. Goiás no contexto Nacional. 2011. Disponível em:

<http://www.seplan.go.gov.br/sepin/down/goiascn2011.pdf) Acesso em abril de 2012.

Silva, W. V. ; SANTO, E. L. ; SILVA, L. S. C. V. Co-integração entre os preços da soja cotados nos mercados brasileiro e norte americano: uma análise empírica. Caderno de pesquisa em administração, São Paulo, v. 10, no 3, p. 69-78, julho/setembro, 2003.

SILVA NETO, W. A., PARRÉ, J.L. Assimetria na transmissão de preços: evidências empíricas. Revista Econômica do Nordeste. , v.43, p.109 - 123, 2012.

URSO, F.S.P. A Cadeia Da Carne Bovina No Brasil: Uma Análise De Poder De Mercado E Teoria Da Informação. 2007. Tese (Doutorado) - Fundação Getulio Vargas - Escola de Economia de São Paulo, São Paulo, 2007.

ZILLI, J. B.; SILVA, A. F; CAMPOS, S. K; COSTA, J. S. Análise da cointegração e causalidade dos preços de boi gordo em diferentes praças nas regiões sudeste e centro-oeste do Brasil. Rev. de Economia Agrícola, São Paulo, v. 55, n. 2, p. 105-119, jul./dez. 2008. 